\title{
Synthesis of jet fuel range cycloalkanes from the mixtures of cyclopentanone and butanal
}

Jinfan Yang ${ }^{\dagger, *, \#}$, Shanshan $\mathrm{Li}^{\dagger, *, *}$, Ning $\mathrm{Li}^{*{ }^{*}}$, Wentao Wang ${ }^{\dagger}$, Aiqin Wang ${ }^{\dagger}$, Tao Zhang ${ }^{\dagger}$, Yu Cong ${ }^{\dagger}$, Xiaodong Wang $^{\dagger}$, George W. Huber ${ }^{*, \xi}$

${ }^{\dagger}$ State Key Laboratory of Catalysis, Dalian Institute of Chemical Physics, Dalian 116023, China

University of Chinese Academy of Sciences, Beijing 100049, China

$\S$ Department of Chemical and Biological Engineering, University of Wisconsin-Madison, Madison, WI 53706, USA.

\#These authors contributed equally.

Corresponding author:

Prof. Ning Li, Tel.: +86-411-84379738, Fax: +86-411-84685940. E-mail: lining@dicp.ac.cn.

Prof. George W. Huber, Tel: +1-608-263-0346; Fax: +1-608-262-5434; E-mail: huber@engr.wisc.edu 
Method for the calculation of butanal conversion and the carbon yields of different compounds in aldol condensation step:

Butanal conversion $(\%)=(1-$ Mole of the butanal detected in the liquid product/Mole of the butanal in the feedstock) $\times 100 \%$

Carbon yield of 2-butylidene-cyclopentanone (i.e. compound 1) $(\%)=$ Mole of the 2-butylidene-cyclopentanone generated during the reaction/Mole of the butanal consumed during the reaction $\times 100 \%$

Carbon yield of 2,5-dibutylidenecyclopentanone (i.e. compound 2) $(\%)=$ Mole of the 2,5-dibutylidenecyclopentanone generated during the reaction/Mole of the butanal consumed during the reaction $\times 200 \%$

Carbon yield of 2-ethylhex-2-enal (i.e. compound 3) $(\%)=$ Mole of the 2-ethylhex-2-enal generated during the reaction/Mole of the butanal consumed during the reaction $\times 200 \%$ 


\section{Method for the calculation of carbon yields in hydrodeoxygenation (HDO) step:}

Carbon yield of $\mathrm{C}_{1}-\mathrm{C}_{5}$ light alkanes $(\%)=$ Total carbon of the $\mathrm{C}_{1}-\mathrm{C}_{5}$ alkanes detected in the gas products per unit time/Carbon fed into the reactor per unit time $\times 100 \%$

Carbon yield of $\mathrm{C}_{8}-\mathrm{C}_{13}$ jet fuel range alkanes (\%) = Sum of carbon in the $\mathrm{C}_{8}-\mathrm{C}_{13}$ alkanes detected in the liquid HDO product/Carbon fed into the reactor $\times 100 \%$

Carbon yield of butylcyclopentane $(\%)=$ Sum of carbon in the butylcyclopentane detected in the liquid HDO product/Carbon fed into the reactor $\times 100 \%$

Carbon yield of 1,3-dibutylcyclopentane $(\%)=$ Sum of carbon in the 1,3-dibutylcyclopentane detected in the liquid HDO product/Carbon fed into the reactor $\times 100 \%$

Carbon yield of $\mathrm{C}_{9}$ oxygenates $(\%)=$ Sum of carbon in the $\mathrm{C}_{9}$ oxygenates detected from the liquid HDO product/Carbon fed into the reactor $\times 100 \%$

Carbon yield of $\mathrm{C}_{13}$ oxygenates $(\%)=$ Sum of carbon in the $\mathrm{C}_{13}$ oxygenates detected from the liquid HDO product/Carbon fed into the reactor $\times 100 \%$ 


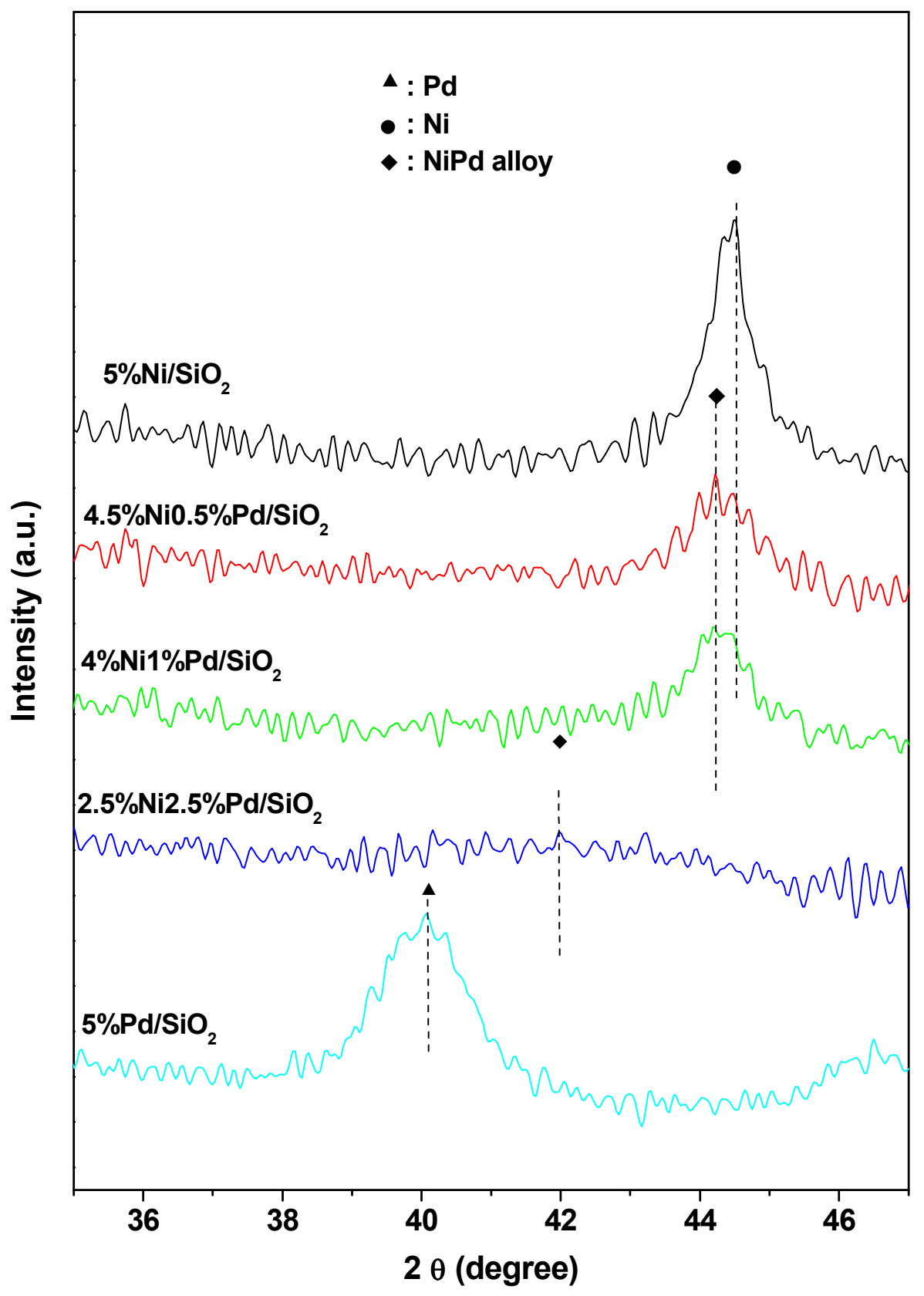

Figure S1. XRD patterns of the $5 \% \mathrm{Ni} / \mathrm{SiO}_{2}, 5 \% \mathrm{Pd} / \mathrm{SiO}_{2}$, and bimetallic $\mathrm{Ni}-\mathrm{Pd} / \mathrm{SiO}_{2}$ catalysts. 

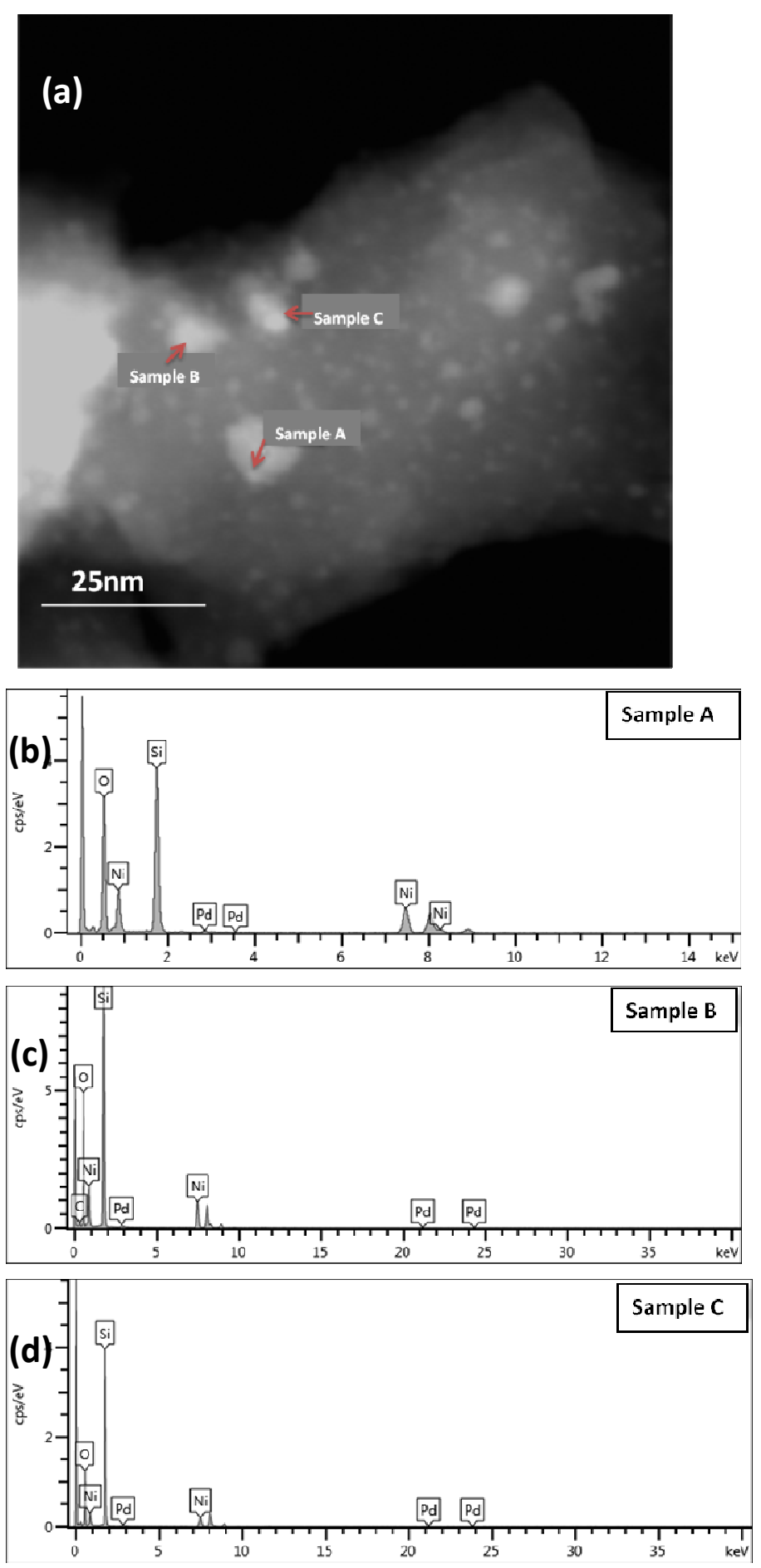

Figure S2. (a) STEM-EDX point spectrum of $4 \% \mathrm{Ni} 1 \% \mathrm{Pd} / \mathrm{SiO}_{2}$ catalyst, (b-d)

Corresponding EDX analysis results for the three randomly chosen particles in (a). 


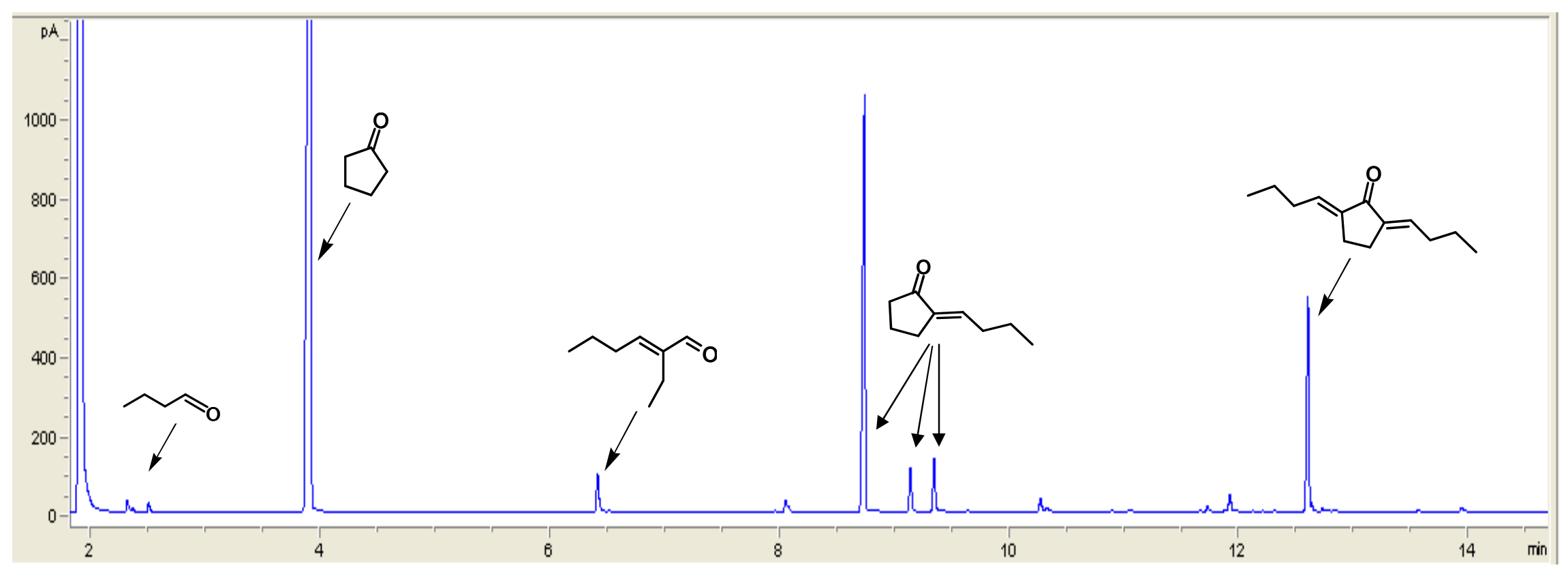

Figure S3. Chromatogram of solvent-free aldol condensation products of cyclopentanone and butanal over MgAl-HT. Reaction conditions: 413

$\mathrm{K}, 4 \mathrm{~h} ; 5.16 \mathrm{~g}$ cyclopentanone, $1.44 \mathrm{~g}$ butanal, $0.14 \mathrm{~g}$ catalyst. 

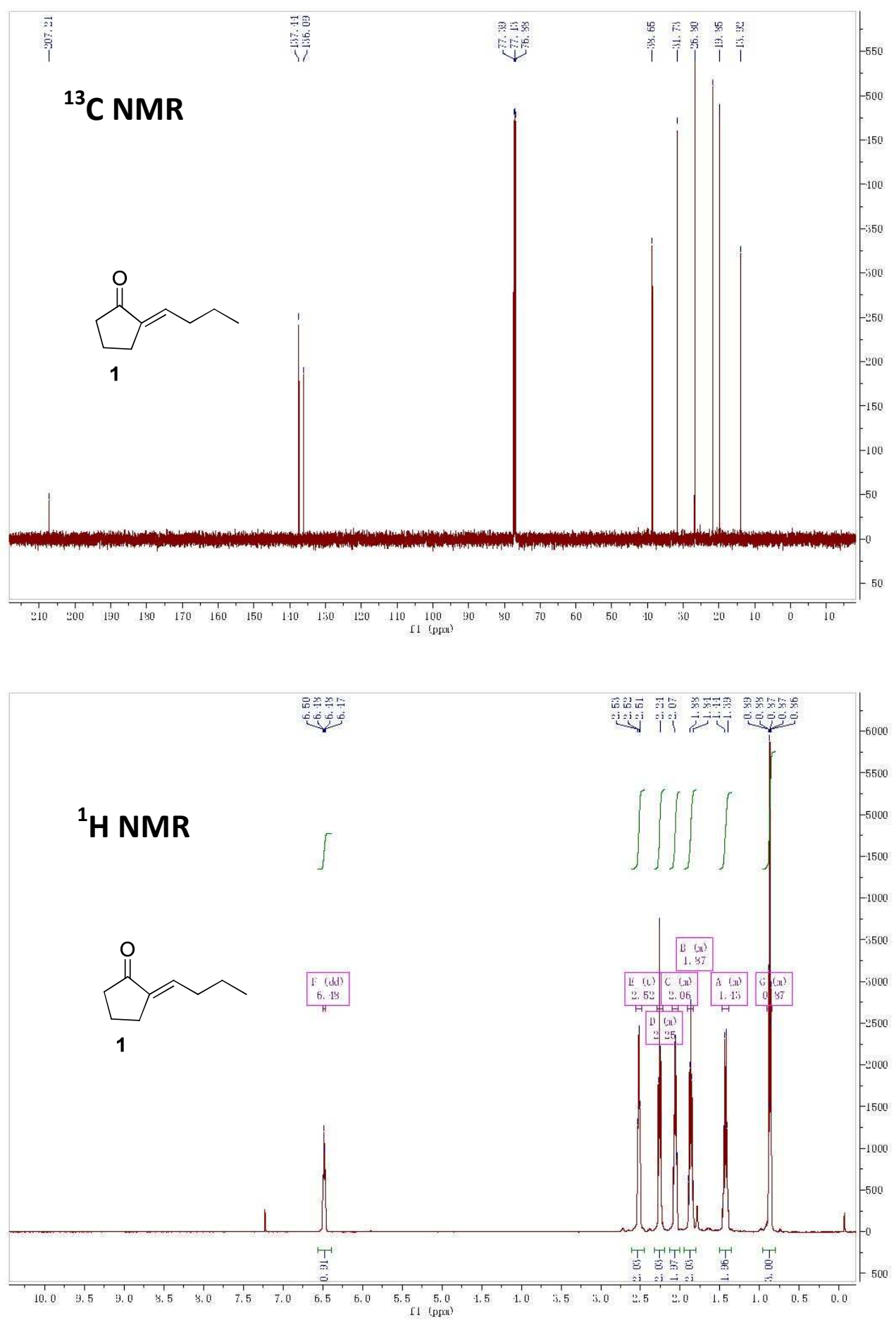

Figure S4. ${ }^{13} \mathrm{C}$ and ${ }^{1} \mathrm{H}$ NMR spectra of compound $\mathbf{1}$ from the solvent-free aldol condensation of butanal and cyclopentanone. 

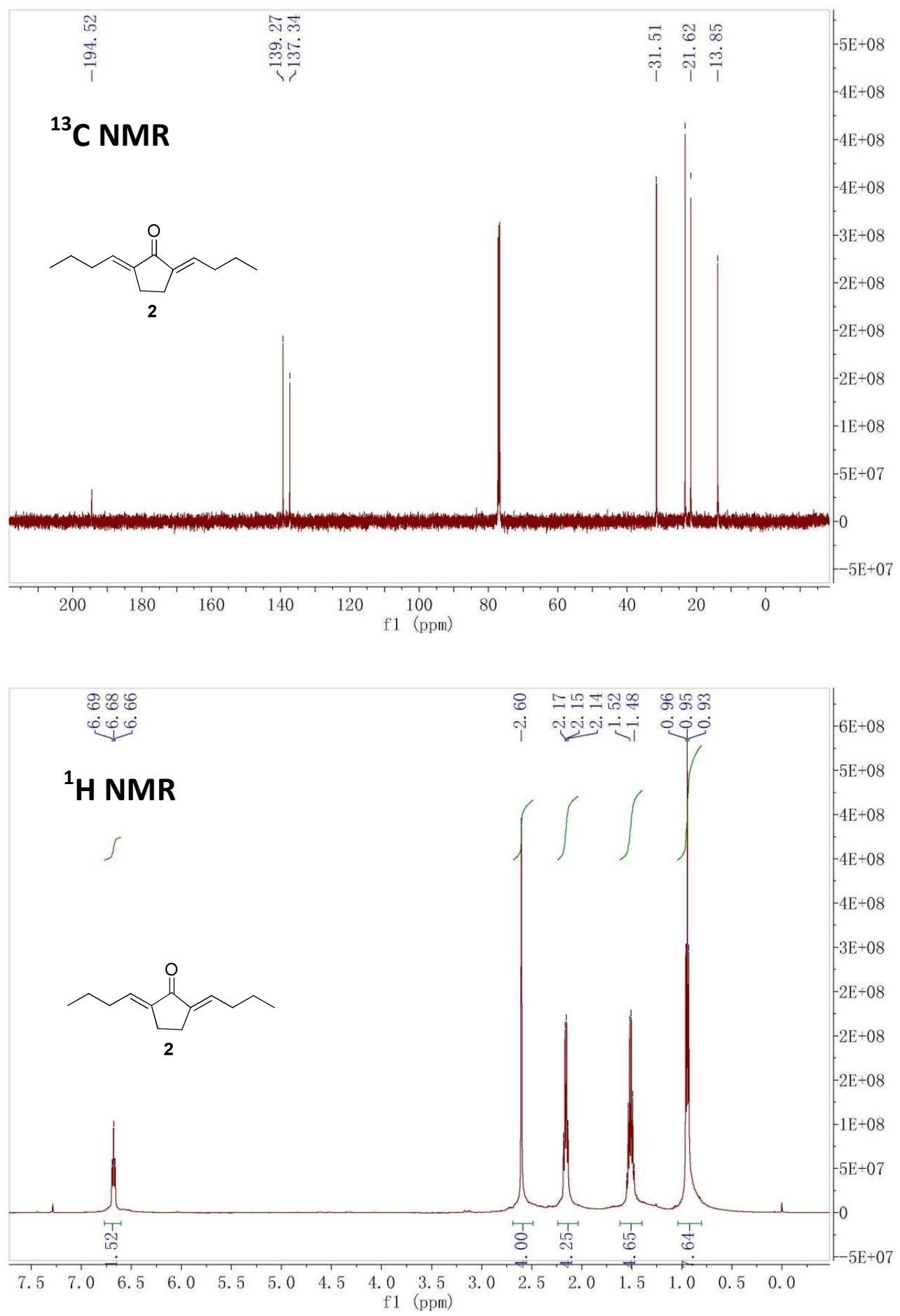

Figure S5. ${ }^{13} \mathrm{C}$ and ${ }^{1} \mathrm{H}$ NMR spectra of compound 2 from the aldol condensation of butanal and cyclopentanone. 


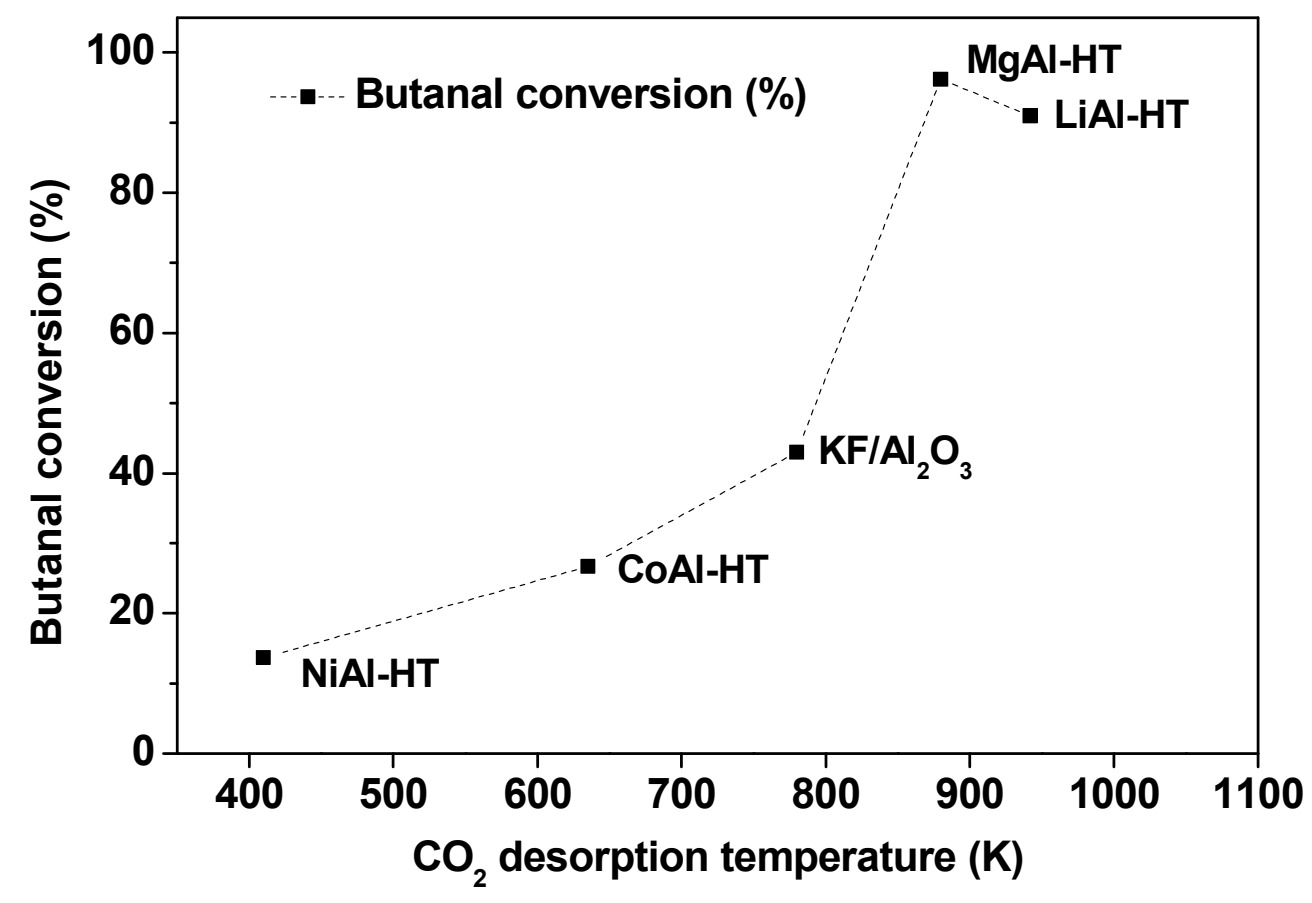

Figure S6. Relationship between the butanal conversion and $\mathrm{CO}_{2}$ desorption temperature over different solid base catalysts. Reaction conditions: $413 \mathrm{~K}, 4 \mathrm{~h}$; $5.16 \mathrm{~g}$ cyclopentanone, $1.44 \mathrm{~g}$ butanal, and $0.14 \mathrm{~g}$ catalyst. 

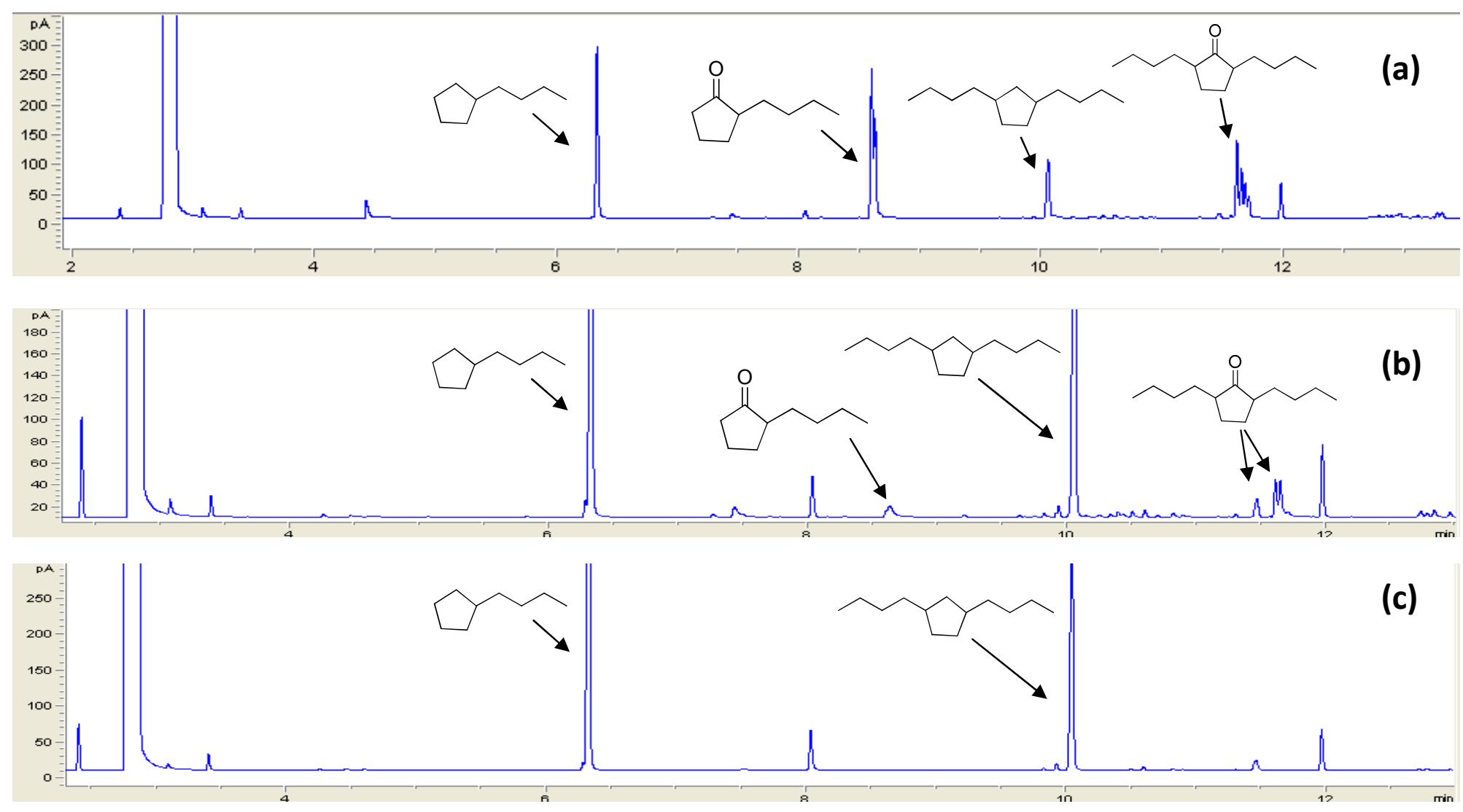

Figure S7. Chromatograms of liquid samples from the $\mathrm{HDO}$ of the aldol condensation products over the $5 \% \mathrm{Ni} / \mathrm{SiO}_{2}(\mathrm{a}), 5 \% \mathrm{Pd} / \mathrm{SiO} 2(\mathrm{~b})$ and $4 \% \mathrm{Ni1} \% \mathrm{Pd} / \mathrm{SiO}_{2}$ (c) catalysts. Reaction conditions: $503 \mathrm{~K}, 1.8 \mathrm{~g}$ catalyst; hydrogen flow rate: $120 \mathrm{~mL}$ min $^{-1}$, liquid feedstock flowrate: $0.04 \mathrm{~mL}$ $\min ^{-1}\left(\mathrm{WHSV}=1.3 \mathrm{~h}^{-1}\right)$. 


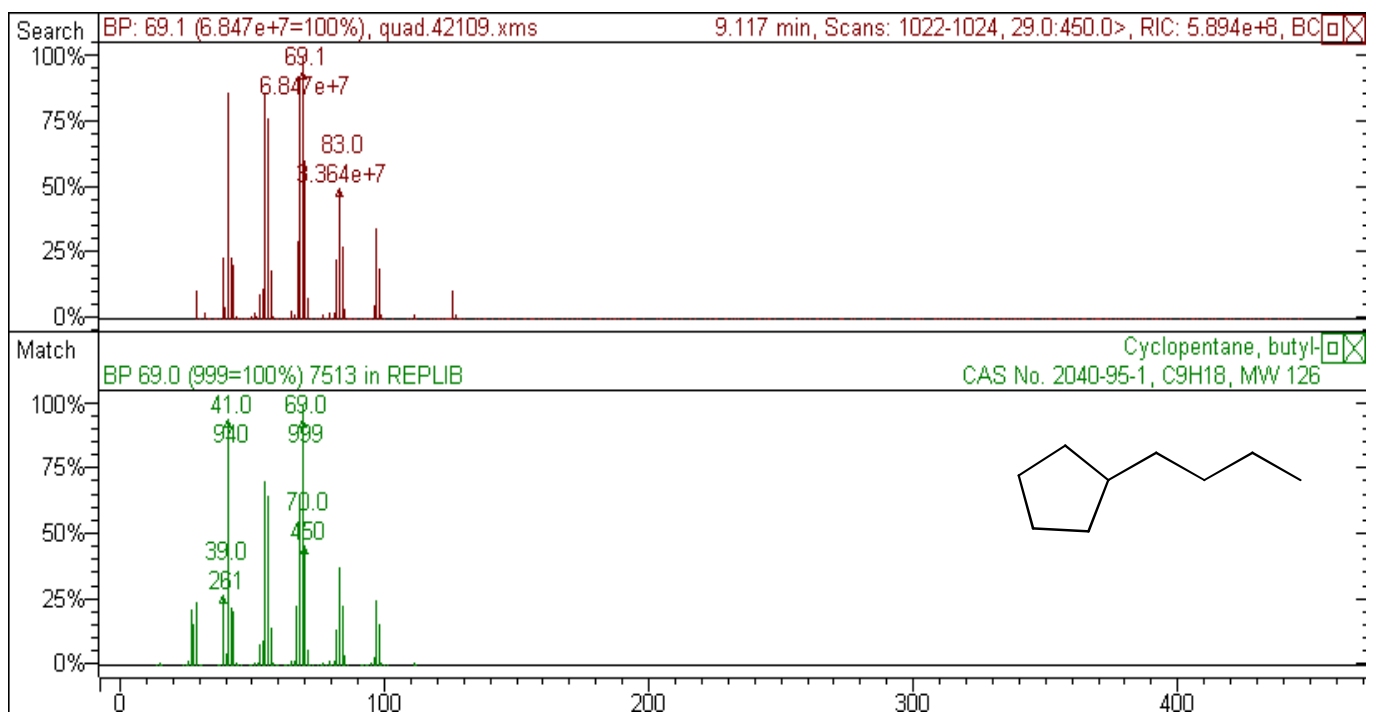

Figure S8. Mass spectrograms of the butylcyclopentane in the $\mathrm{HDO}$ products over the $5 \% \mathrm{Ni} / \mathrm{SiO}_{2}$ catalyst. 


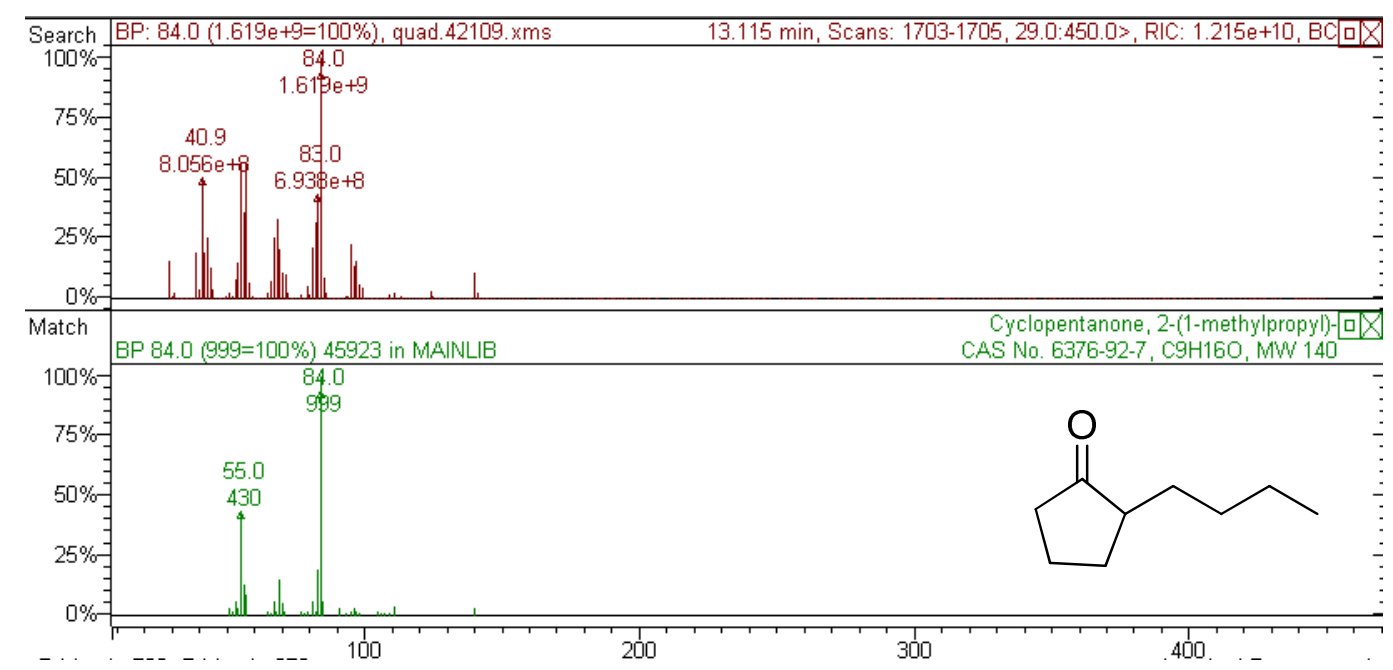

Figure S9. Mass spectrograms of the 2-butylcyclopentanone in the $\mathrm{HDO}$ products over the $5 \% \mathrm{Ni} / \mathrm{SiO}_{2}$ catalyst. 


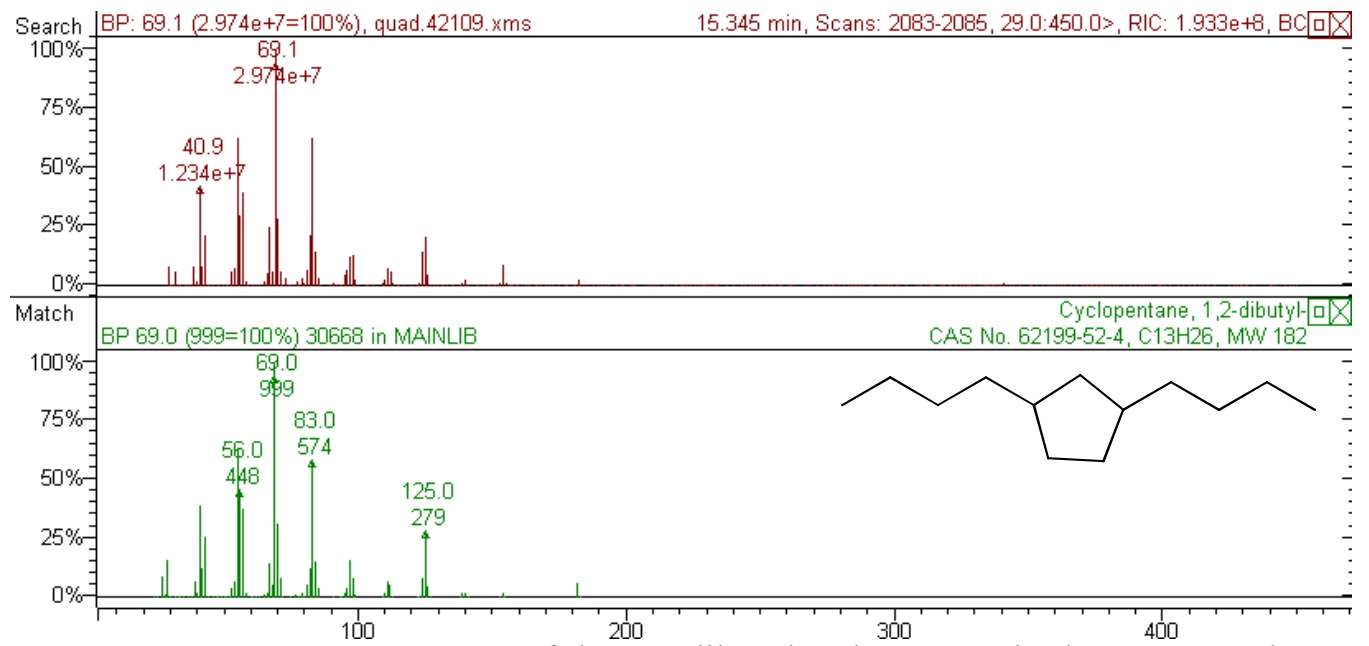

Figure S10. Mass spectrograms of the 1,3-dibutylcyclopentane in the HDO products over the 5\% $\mathrm{Ni} / \mathrm{SiO}_{2}$ catalyst. 


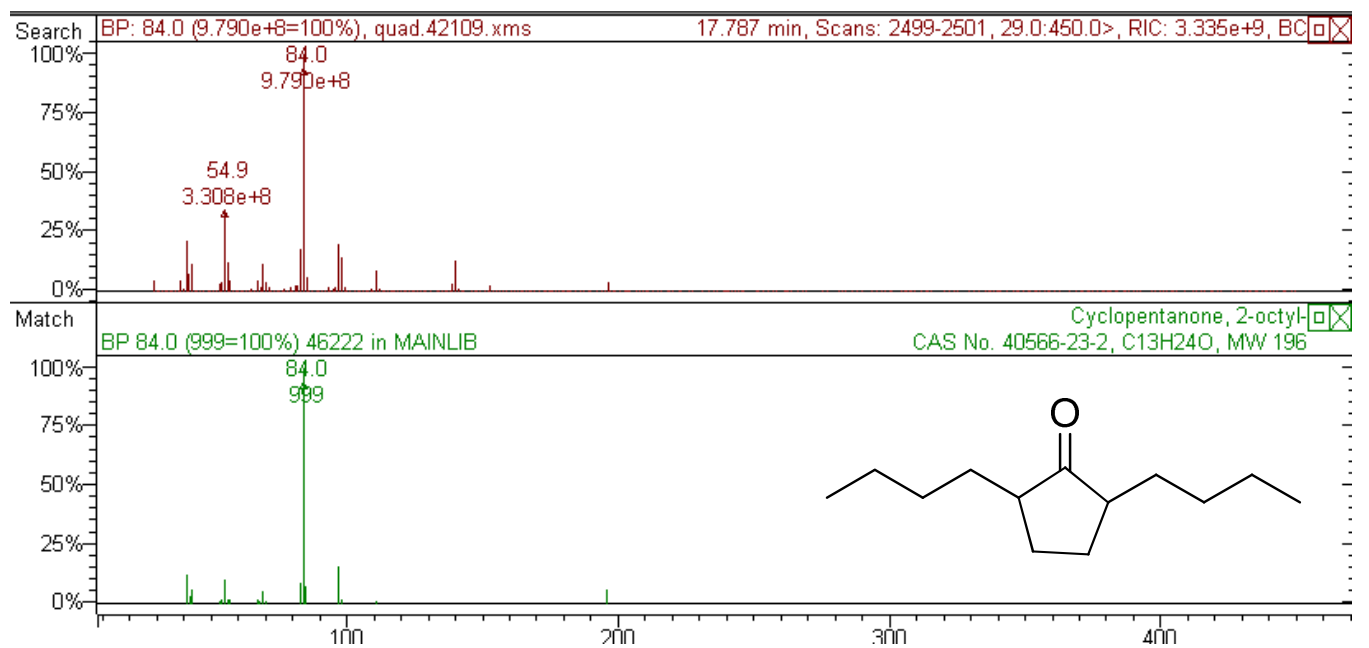

Figure S11. Mass spectrograms of the 2,5-dibutylcyclopentanone in the HDO products over the 5\% $\mathrm{Ni} / \mathrm{SiO}_{2}$ catalyst. 
Table S1. The actual Ni and Pd contents in the HDO catalysts measured by ICP analysis.

\begin{tabular}{lll}
\hline Catalyst & \multicolumn{2}{l}{ Metal content $^{a}$} \\
\cline { 2 - 3 } & $\mathrm{Ni}(\%)$ & $\mathrm{Pd}(\%)$ \\
\hline $5 \% \mathrm{Ni} / \mathrm{SiO}_{2}$ & 4.5 & 0 \\
$4.5 \% \mathrm{Ni} 0.5 \% \mathrm{Pd} / \mathrm{SiO}_{2}$ & 4.2 & 0.6 \\
$4 \% \mathrm{Ni} 1 \mathrm{Pd} / \mathrm{SiO}_{2}$ & 3.8 & 0.9 \\
$2.5 \% \mathrm{Ni} 2.5 \% \mathrm{Pd} / \mathrm{SiO}_{2}$ & 2.4 & 2.1 \\
$5 \% \mathrm{Pd} / \mathrm{SiO}_{2}$ & 0 & 4.5 \\
$\mathrm{SiO}$ & - & - \\
\hline
\end{tabular}

${ }^{a}$ Weight percentage of $\mathrm{Ni}$ and $\mathrm{Pd}$ in the catalysts. 